\title{
A cuarenta años del golpe de Estado en Chile. Vías para repensar la relación entre violencia y política
}

\section{Forty years from the coup in Chile; ways to rethink the relation between violence and politic}

\author{
Javier Rebolledo (2013), El Despertar de los cuerVos. Tejas Verdes, \\ EL origen DEL EXTERMinio EN Chile, Ceibo ediciones, SANTiago de \\ Chile, 384 PP. ISBN 956907 I 400
}

El 2013 fue particular en la historia contemporánea de Chile: a fines de ese año, Michelle Bachelet fue reelecta, por primera vez en la historia reciente, presidenta del país con una diferencia de votos enorme con respecto a su contrincante de la derecha Evelyn Matthei. Ambas candidatas representan simbólicamente un conflicto originado hace ya varias décadas, por una parte, Michelle Bachelet es hija de Alberto Bachelet, general de la Fuerza Aérea de Chile, muerto de un infarto en 1974 tras sufrir reiteradas torturas realizadas por otros miembros de la aviación; por otra, Evelyn Matthei es hija de Fernando Matthei, comandante en Jefe de la Fuerza Aérea y miembro, a partir de 1978, de la Junta Militar de Gobierno, relacionado, por la Agrupación de Familiares de Ejecutados Políticos, con la muerte de Alberto Bachelet.

Coincidencia o no, la campaña presidencial de ese año revivió, muchas veces de manera forzosa, el antagonismo entre izquierda y derecha que define todavía a gran parte del electorado: ser de izquierda significa estar en contra del golpe de Estado y haber votado no en el plebiscito realizado en 1988 relativo a la continuidad de los militares en el poder; ser de derecha significa estar a favor de la dictadura y haber votado si en dicho plebiscito. La inclusión del Partido Comunista en la coalición de gobierno contribuyó a crear esta imagen de polarización institucional. El lema de la Nueva Mayoría, a la postre vencedora en las elecciones, fue Todos contra la derecha.

La conmemoración de los cuarenta años del golpe de Estado contribuyó bastante a reforzar esta imagen. A este respecto, en la televisión abierta, se elaboró una programación especial relativa a este periodo: en Canal 13 se exhibieron los programas Los mil dias y Once intimo; canal 7 
(Canal del Estado) reestructuró sus programas de entrevista regulares; Chilevisión exhibió una serie dramática realizada por el prestigioso cineasta chileno André Wood llamada Ecos del desierto donde se narra la historia de lucha de Carmen Hertz, abogada y defensora de los derechos humanos, cuyo marido fue asesinado en 1973 por la operación conocida como Caravana de la muerte; finalmente, el canal La Red, a través de su programa regular Mentiras verdaderas, dedicó una semana especial a la conmemoración del golpe, donde se entrevistaron a víctimas de violaciones a los derechos humanos, así como al hijo del exjefe de la Dirección de Inteligencia Nacional (Dina), principal organismo represor a inicios de la dictadura (1973-1977).

La conclusión parece bastante clara: el país en su conjunto, independiente de su color político, condena las violaciones a los derechos humanos. La reconciliación nacional es posible solamente si nos comprometemos como país a que nunca más llegaremos a dirimir nuestros conflictos mediante la violencia y la barbarie. En el mismo espíritu, Hernán Larraín, expresidente de la Unión Demócrata Independiente, partido que alberga a la mayoría de civiles ligados a la dictadura, pidió perdón por las violaciones a los derechos humanos cometidas tras el golpe de Estado. Asimismo, Camilo Escalona, expresidente del Partido Socialista, partido donde militaba el expresidente Salvador Allende, pidió perdón por haber contribuido a la polarización social que pareciera haber gatillado el golpe.

El presidente Sebastián Piñera, militante de Renovación Nacional (segundo partido de mayor importancia de la derecha), no quiso estar ajeno a la conmemoración: rememoró la gran obra realizada por la dictadura militar, refieriéndose en duros términos a la colaboración de políticos de su sector en la represión ejercida durante esa época. Llamó a esta participación de civiles en el gobierno militar como una complicidad pasiva respecto a la sistemática violación a los derechos humanos.

Con el mismo afán, Piñera cierra el Penal Cordillera, que al igual que Punta Peuco fueron construidos exclusivamente para militares condenados por violaciones a los derechos humanos, con el fin de separarlos de los reclusos ordinarios. Ambos centros de reclusión han generado enorme polémica en el país por los privilegios que ostentan los exmilitares, lo que contrasta con las condiciones infrahumanas en que se encuentran los presos comunes. Lo paradójico del cierre del Penal Cordillera es que fue realizado por un presidente de derecha, mientras que su construcción fue promovida por el expresidente socialista Ricardo Lagos, supuestamente para reducir la población del penal Punta Peuco, el cual alberga actualmente a 18 personas.

Más allá de las diferencias políticas, izquierda y derecha institucionales están de acuerdo: el país vivía una polarización indeseable, una suerte 
de esquizofrenia social a fines de los ańos sesenta que hizo inevitable la intervención militar, como se le suele decir eufemísticamente al golpe de Estado. Lo condenable no es, a este respecto, la ruptura (política) de la democracia, sino los excesos cometidos por militares (no políticos) a víctimas (no militantes). De este modo, se podría constatar una cierta continuidad entre la obra del régimen militar y los gobiernos democráticos, salvo por el paréntesis de salvajismo que constituyó la violación de los derechos humanos. No la de algunos humanos con militancia de izquierda, sino la de todas los humanos. Así, uno podría realizar la hipótesis siguiente: la gobernabilidad democrática de Chile en el presente se sustenta sobre la negación del posible vínculo entre violencia y política.

\section{El cuerpo como lugar de memoria}

La política institucional en Chile se ha construido sobre una evidencia histórica bastante particular: la violencia, en general, es algo externo a la política. La obra del régimen militar se evalúa principalmente según si constituye o no un progreso para el desarrollo económico del país, dejando de lado el momento fundacional que representa la violencia en él, la cual se caracterizó por un aniquilamiento masivo de las fuerzas políticas opositoras ${ }^{1}$. El problema de fondo pareciera ser, entonces, bastante más parcial: el orden en Chile no se relaciona o se relaciona muy poco con la violencia ejercida en dictadura, hay temas judiciales por resolver, pero que sólo afectan a víctimas y victimarios.

En los últimos años, más allá de los informes oficiales construidos al respecto (Informe Rettig, 1990; Informe Valech, 2011), historiadores y periodistas, principalmente, se han dedicado a reconstruir los trazos de la represión y violencia en Chile. Entre los libros más destacados quisiéramos nombrar: Las letras del horror, dos tomos, de Manuel Salazar, en 2011 y 2012; Villa Grimaldi (Cuartel Terranova) Historia, testimonio, reflexión, de Gabriel Salazar en 2013; Retorno a Dawson, de Miguel Lawner, reeditado en 2012, todos publicados por LOM Ediciones.

Sumado a estos estudios, Javier Rebolledo, joven periodista, realiza un aporte fundamental a la exploración de la violencia política ejercida en dictadura: publicó un libro en 2012 sobre las vejaciones y ejecuciones cometidas en el cuartel "Simón Bolivar" de la Dina La danza de los cuervos. El destino final de los detenidos desaparecidos, de la casa editora Ceibo Ediciones, en 2013; a cuarenta ańos del golpe de Estado en Chile, una

\footnotetext{
${ }^{1}$ Cabe recordar que entre ejecutados, torturados, detenidos desaparecidos y presos políticos, las víctimas del régimen sobrepasan a las cuarenta mil personas, de las cuales más de tres mil fueron ejecutadas o desaparecidas.
} 
nueva investigación titulada El despertar de los cuervos. Tejas Verdes, el origen del exterminio en Chile, correspondiente también a Ceibo Ediciones.

En este libro, Rebolledo reconstruye la historia del centro de detenciones Tejas Verdes - dirigido por el futuro jefe de la Dina, Manuel Contreras- a partir de cuatro testimonios de víctimas y el testimonio de un militar inicialmente implicado. El libro está estructurado en cuatro partes (I. El origen, II. Los sueños y los tormentos, III. La expiación de los pecados, y IV. Los caminos) donde articula de forma eficaz la información obtenida directamente a través de los testimonios y la correspondiente a fuentes secundarias. Además, el libro incluye bastantes fotos que permiten ponerles rostro a aquellas personas que los informes tratan usualmente como casos.

En este centro, según indica el autor, se experimentó respecto a las posibilidades del cuerpo para resistir la tortura. Por ello, es uno de los centros que presenta mayores muertes (sin ser directamente un centro de exterminio); en la mayoría de los casos, resultado de excesos cometidos en la tortura misma. Este libro no es un informe sobre la violencia, sino una superficie de inscripción de la experiencia de la violencia.

Lo primero que llama la atención, evidentemente, es la crudeza de los testimonios. Difícilmente uno podría imaginar las variantes que la violencia y la crueldad ofrecen. Tal como lo sugiere Agamben, en los campos de concentración la vida se presenta desnuda. El cuerpo está a disposición entera del poder. Una primera tarea es despersonalizar a la víctima. Carevic, jefe del campo de prisioneros, lo deja rápidamente en claro: "Nunca más por el nombre. ¿Entendieron? -les dijo en la formación-. A partir de hoy son un número" (p. 135). Luego eliminar el género: "Una de las primeras medidas del teniente Carevic fue cercar el campo y separarlas totalmente de los hombres" (p. 126).

La sexualidad desaparece, no hay elección posible, dentro del campo está prohibido ser sujeto: "No había forma de detenerlos. No querían saber nada de nada. Primero la penetró uno. Y sus gritos: no, por favor, los iba a acusar, los iba a acusar. Jamás un hombre había estado ahí y el recuerdo y los sueños con Juan Carlos. 'El hombre me violó hasta acabar. Luego vino el segundo, hasta acabar también. Y también el tercero y un cuarto. Hasta ahí alcancé a contar. Después de eso me desmayé”' (p. 189).

Frente al cuerpo desnudo, sin nombre, sin género, el dolor no es simplemente intensidad, tiene forma, olor: cuando le cauterizaban una herida con una plancha, "y el dolor de mi propia piel quemada. Muy parecido a los recuerdos del sur, cuando un chancho se enfermaba y los jefes le pedían a mi papá que lo quemara” (p. 300).

La violencia ejercida sobre el cuerpo busca eliminar la diferencia, lo heterogéneo de la experiencia humana. No hay diferencia significativa. 
Todo es masa amorfa, homogénea, maleable, disponible para su uso. Es por ello que el excomandante en Jefe de la Armada y miembro de la Junta de Gobierno, José Toribio Medina se refería a los militantes comunistas como humanoides.

Lo segundo que llama la atención es el perfil de los torturados. La mayoría de las veces tienen un escaso poder: Ana y Olga, militantes del Movimiento de Izquierda Revolucionaria (MIR), de diecisiete y dieciséis años, respectivamente, y Feliciano, sin militancia política, cuyo único pecado fue ser hermano de un dirigente sindical del mIR que huyó el mismo 11 de septiembre. El único testimonio de una persona con participación activa en el gobierno de la Unidad Popular es el de Anatolio, militante del Partido Socialista, representante del gobierno en el directorio de la Pesquera Arauco.

No quisiera sugerir que en un caso la tortura es justificada y en los otros tres, no, sino que, a ratos, es difícil encontrar una utilidad detrás de la tortura. Si bien éstas se inscribían la mayor parte de las veces en interrogatorios, cuyo fin era recabar información relevante respecto al declarado enemigo, el dolor también podía ser absurdo, inútil, sólo gasto. Por no aprenderse un himno militar, "Carevic le ordenó a Olga regar el patio entero con una cuchara de té. Todo el día, desde la mañana hasta la noche. Sin tomar agua, sin comida, custodiada" (p. 130).

La violencia, de este modo, no aparece como un recurso, un medio para lograr algo, sino como un fin en sí mismo. Tal como lo afirma Ricœur a propósito de la lectura de Arendt del totalitarismo, "la posibilidad del mundo totalitario hay que buscarla en una meditación sobre el mal radical". La violencia no está fuera de la política. Javier Rebolledo nos muestra cómo en centros infames se está construyendo el nuevo orden, se están produciendo sujetos, se están fijando identidades. Es en este sentido que el libro nos abre a la experiencia del mal, de la violencia inútil, de aquello que no puede ser simplemente excluido de lo razonable.

"Los abusos estaban a la orden del día. Había llegado a pensar que era una forma de adoctrinarlas, de hacerlas mejores personas. Una especie de ser humano nuevo, con una receta que combinaba golpes, aislamiento, tortura y rigidez" (p. 130).

Toda construcción deja rastros, huellas. El despertar de los cuervos expone una muestra de esos vestigios. Representa un relato fundamental acerca de la historia reciente. El orden en Chile ha sido construido con base en esta violencia. Los cuerpos de las personas torturadas son nuestra mancha de nacimiento. Actualmente, la violencia física es cada vez menos necesaria, basta con excluirla del discurso político para que sea efectiva. La criminalización de la protesta, la persecución del pueblo mapuche, la ley antiterrorista son todos dispositivos que permiten poner 
los conflictos sociales entre paréntesis y poder así administrarlos. Sin embargo, tal como lo señala Foucault, el límite a la obediencia es el cuerpo vivido. Al interior del encierro, de la tortura, de la indefensión se crearon solidaridades, amores, tácticas individuales y colectivas de resistencia. La dictadura fracasó.

Conmemorar los cuarenta años del golpe de Estado en Chile no significa solamente recordar un acontecimiento traumático en nuestro pasado reciente, significa también pensar de nuevo el lugar que tiene la violencia en la construcción del orden social, significa reflexionar en torno al valor político de ésta, comporta una oportunidad fundamental para reintegrarla en nuestra historia. Libros como el de Javier Rebolledo nos muestran que todavía tenemos tiempo; aún quedan testigos que nos pueden ayudar.

\section{Bibliografía}

Informe Rettig (1990), "Informe de la comisión nacional de verdad y reconciliación”, Corporación Nacional de Reparación y Reconciliación, Santiago de Chile.

Informe Valech (2011), "La Comisión Asesora para la Calificación de Detenidos Desaparecidos, Ejecutados Políticos y Víctimas de Prisión Política y Tortura”, Comisión Nacional sobre Prisión Política y Tortura, Santiago de Chile.

Recibida: 13 de diciembre de 2013. Aceptada: 10 de febrero de 2014.

Nicolás Angelcos-GutiérReZ Universidad Diego Portales Correo-e: nicolasangelcos@gmail.com

Nicolás Salvador Gregorio Angelcos Gutiérrez. Es doctorante en sociología, bajo la dirección de Michel Wieviorka, en la École des Hautes Études en Sciences Sociales, París. Actualmente es profesor de la Escuela de Sociología de la Universidad Diego Portales. Es miembro del Núcleo Teoría Social en la misma universidad. Su línea de investigación actual es sociología de los movimientos sociales. Entre sus últimas publicaciones destacan: en coautoría: 'L' 'expérience participative' des pobladores au Chili: entre résistance aux modes de gestion de la pauvreté et nouvelles formes de politisation" Revue Lien Social et Politiques, 71, Montréal, Ca- 
nadá, en proceso de publicación (2014) ; en coautoría, "La reconstruction de la mémoire de la dictature par les jeunes militants syndicaux et 'pobladores' au Chili", Revue Émulations, 11, Lovaina, Bélgica (2013); "Casonas ocupadas y lucha por la vivienda en el casco histórico de Santiago de Chile", Revista Interdisciplinaria de Trabajos sobre las Américas, 6, París, Francia (2013); "Lucha por la vivienda y politización de las trayectorias individuales", Revista Polis, 31, Santiago, Chile (2012). 